Article

\title{
Environmental Sustainability of Pasta Production Chains: An Integrated Approach for Comparing Local and Global Chains
}

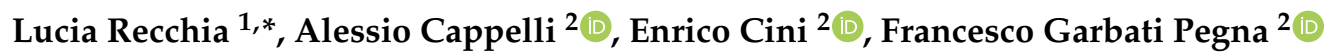 \\ and Paolo Boncinelli ${ }^{2}$ \\ 1 Department of Innovation and Information Engineering, Università degli Studi Guglielmo Marconi, \\ via Plinio 44, 00193 Rome, Italy \\ 2 Department of Agricultural, Food and Forestry Systems (GESAAF), University of Florence, Piazzale delle \\ Cascine 16, 50144 Firenze, Italy; alessio.cappelli@unifi.it (A.C.); enrico.cini@unifi.it (E.C.); \\ francesco.garbati@unifi.it (F.G.P.); paolo.boncinelli@unifi.it (P.B.) \\ * Correspondence: 1.recchia@unimarconi.it
}

Received: 2 December 2018; Accepted: 13 March 2019; Published: 20 March 2019

check for updates

\begin{abstract}
Major pasta industries have started to evaluate the environmental footprint of their productions exploiting both Life Cycle Assessment (LCA) and, in some cases, Environmental Product Declaration (EPD) methodologies. In this research, two different pasta production chains were considered: a "high-quality pasta" chain (referred here as "local or regional scenario"), which follows traditional procedures in a Tuscan farm that uses only ancient wheat varieties; and a "conventional pasta" one (referred here as "global or industrial scenario"), in which pasta is produced using national and international grains, following industrial processes. An integrated methodology based on both an Environmental Impacts ANalysis (EIAN) approach and the LCA has been developed, analyzing five environmental compartments (i.e., soil, water, air, resources, climate change) and a total number of ten expected environmental pressures. As a result, the high-quality pasta chain shows a better performance in terms of risk reduction of soil degradation and agrobiodiversity loss, as well as the consumption of non-renewable resources; this is mainly due to the use of lower quantity of chemicals, a lower mechanization level in the agricultural phase, and the use of ancient grains. However, the conventional pasta chain prevails in terms of a more efficient exploitation of land and water resources, due to higher yields and the use of more efficient sprayers, and also in reducing noise emitted by the overall production equipment.
\end{abstract}

Keywords: durum wheat environmental sustainability; ancient grains; pasta production; environmental impacts analysis; Life Cycle Assessment (LCA)

\section{Introduction}

Pasta is defined as any kind of shaped product obtained by extruding or forming a dough prepared with (unrefined or not) durum wheat semolina flour, added with water and (optionally) eggs and other flours or ingredients [1]. Italian regulations set more restrictive rules on pasta ingredients as the D.P.R. (Decree of the President of the Italian Republic) n.187/2001 provides the following definitions:

- "Durum wheat semolina" or simply "semolina" is referred to as a rough, granular product obtained by grinding and sifting durum wheat, removing all impurities and extraneous bodies;

- "Durum wheat semolina pasta" is referred to as any product obtained by drawing, rolling, and drying a dough prepared only with durum wheat semolina and water. 
Between 2012 and 2014, the production of pasta in the European Union increased from 4544 to $4752 \mathrm{kton} /$ year, with a correspondent growth in pasta consumption from 3315 to $3637 \mathrm{kton} /$ year.

Large industries usually provision their durum wheat supplies on the international commodity market, Canada and Mexico being the main exporters. In Italy, however, main pasta producers preferably use durum wheat coming from the national market, integrating their supplies with products mainly from France, U.S.A., and Australia [2-8].

As a consequence, the environmental impact of this production sector can be significant, and this has pushed major pasta industries to start evaluating the environmental footprint of their productions by means of Life Cycle Assessment (LCA) and, in some cases, even by Environmental Product Declaration (EPD), according to the standards of the International Organization for Standardization (ISO standards) [9-11], making information widely available. The reasons supporting this choice are mainly due to the increasing attention of final consumers on the possible impacts of industrial production on the environment, which determined a growing public pressure on this thematic $[12,13]$. Furthermore, the renewed interest of consumers in ancient grains has promoted an increase in their cultivation and use, expanding the number of products offered by the baking industry [14]. This has also contributed to the safeguarding of biodiversity and to the development of a local micro-economy, which allows local producers to increase their profits by differentiating their products [15]. The planet protection policy has induced many national and international organizations to support sustainable development, production, and consumption strategies with business support policies [16]. On the contrary, smaller producers usually find it difficult to access this support, especially for niche products, such as pasta and bakery products made following traditional procedures or using ancient wheat varieties. Consequently, very few data are available for environmental analysis in this field in reference databases. In addition, systems of food production have strong national specificities [17].

Bevilacqua et al. [18] identify these life cycle phases in the whole production process of pasta: durum wheat cultivation; milling of durum wheat to obtain semolina; pasta production and packaging; transportation and distribution of final products; domestic consumption, waste and pallet disposal. These phases are also mentioned and quantified in the product category rules and reports of the International EPD ${ }^{\circledR}$ System (EPD International AB, Stockholm, Sweden) for industrial pasta producers.

Wheat cultivation is the most variable and, at the same time, fundamental stage. Tillage and all other operations involving soil treatment have the purpose of creating favorable conditions for seed germination and growth, exploiting different techniques. Traditional practices used in Italy chop residuals of the previous crop, use a moldboard plough to dig the ground at a depth of 0.30 to $0.35 \mathrm{~m}$, and harrow it with one or more passages of a disc harrow. All these operations are carried out as soon as possible after harvesting the previous crop (typically on July, in central Italy). Sowing of durum wheat is done in mid-autumn with the use of a universal seed drill, and, more rarely, employing pneumatic seeders. The spacing between rows varies from 0.14 to $0.18 \mathrm{~m}$ while seed depth varies between 20 and $50 \mathrm{~mm}$. The quantity of distributed seed is approximately 180 to $200 \mathrm{~kg}$ per hectare. In durum wheat cultivation performed on a large industrial scale, a minimum tillage is often used with herbicide application before seeding to control weeds. In this case, sowing is done with a direct or combined seed drill, which typically releases up to $220 \mathrm{~kg}$ of seed per hectare at a depth of about $50 \mathrm{~mm}$ and a 0.2 to $0.3 \mathrm{~m}$ row spacing, even if much lower quantities are used in some countries, such as in southern Australia [4,7]. Fertilizers are applied at variable rates, depending on the soil characteristics: values up to $300 \mathrm{~kg} / \mathrm{ha}$ of $\mathrm{N}$ are quite common in worse conditions. For what concerns the growing period, this occurs from late autumn to late spring all around the world. Watering is usually required in driest areas to achieve satisfactory productivity and quality levels.

In this work, the environmental sustainability of two different pasta production chains was evaluated: The first concerns the production of "high-quality pasta" which is accomplished by following traditional production procedures on a Tuscan farm that use only ancient wheat varieties (referred here as "local or regional scenario"); in the second, a "conventional pasta" is produced using national and international grains and following industrial processes (referred here as "global or 
industrial scenario"). Results of this analysis are presented and discussed here, comparing the two chains in terms of their environmental impacts throughout the whole production process, and drawing some conclusions. Moreover, an integrated methodology based on an Environmental Impacts ANalysis (EIAN) and the LCA has been developed, investigating five environmental compartments (i.e., soil, water, air, resources, climate change) and a total number of ten expected environmental pressures. This developed methodology assures a comprehensive environmental evaluation of the products: Using the EIAN approach (see Section 2.1.1), the site-specific impacts can be assessed through qualitative and/or qualitative indicators, to integrate the results usually obtained by the LCA or the EPD implementation.

\section{Materials and Methods}

\subsection{Description of the Methodology for the Environmental Assessment}

This work assesses the environmental pressures associated with the production of high-quality and conventional pasta. These two production systems imply different approaches in terms of agricultural management, logistics, industrial plant optimization, etc.

To achieve this goal, an integrated methodology based on both site-specific and global evaluations has been developed. A number of both quantitative and (few) qualitative indicators have been considered to investigate the different characteristics of the two production systems, as well as their environmental impacts. Several European projects working on biofuels production adopt a similar methodology integrating local impacts evaluation with the LCA, not only for the agricultural phase but also for the logistic and industrial phases [19-21]. This approach can assure a comprehensive environmental assessment of the products.

The present study considered 5 different environmental compartments (i.e., soil, water, air, resources, climate change) and a total number of 10 expected environmental pressures, as illustrated in Figure 1. For each pressure, specific indicators were set with the aim of evaluating both local and global consequences of production processes. Table 1 illustrates the environmental indicators (described in more details in Sections 2.1.1 and 2.1.2) considered for each production phase as regards the analyzed environmental pressures. Afterwards, indicators are evaluated for each of the proposed scenarios to compare them in terms of their performance, with respect to the environmental pressures. A comprehensive performance is defined by assigning a value of 2 (worst performance), 1 (equivalent performance) or 0 (better performance) for each indicator, and, then, by summing all values related to each pressure (see Table 1), and obtaining a total score for it. The higher each score is, the lower the corresponding performance. Lower performances are highlighted in red, while higher performances are colored in green; equivalent scores correspond to equivalent performances and are colored in yellow. As a consequence, it is possible to compare the two scenarios considered in this study.

\begin{tabular}{|llll|}
\hline A - Soil & B - Water & C - Air & D - Resources \\
- Land use (A1) & - Pollution (B4) & - Pollution (C6) & - Biotic: agrobiodiversity (D8) \\
- Pollution (A2) & - Abstraction or & - Noise (C7) & - Abiotic: non renewable (D9) \\
- Degradation (A3) & Diversion (B5) & E- Climate change (E10) \\
\hline
\end{tabular}

Figure 1. Environmental compartments and pressures under investigation. 
Table 1. Environmental Impacts ANalysis (EIAN) and Life Cycle Assessment (LCA) indicators considered for the environmental assessment.

\begin{tabular}{|c|c|c|c|}
\hline Investigated Aspect & $\begin{array}{l}\text { Environmental } \\
\text { Pressure }\end{array}$ & $\begin{array}{l}\text { Local Indicator } \\
\text { (EIAN Approach) }\end{array}$ & $\begin{array}{l}\text { Global Indicator } \\
\text { (LCA Methodology) }\end{array}$ \\
\hline \multicolumn{4}{|l|}{ 1. Agricultural phase } \\
\hline \multirow{4}{*}{ Crop choice } & A1 & - average yield & - \\
\hline & $\mathrm{A} 2, \mathrm{~B} 4$ & $\begin{array}{l}\text { - agrochemicals typology and } \\
\text { quantity }\end{array}$ & - \\
\hline & B5 & - WUE of cultivar & - CMR \\
\hline & D8 & - adoption of autochthon cultivars & - \\
\hline \multirow{3}{*}{ Soil management } & A3 & - mechanization level & - \\
\hline & D9 & - fuel volume & - CER, CMR \\
\hline & E10 & - & - $\mathrm{CO}_{2}$ eq emissions \\
\hline \multirow{3}{*}{ Fertilisers use } & B4 & - fertilizers typology and quantity & - Eutrophication \\
\hline & D9 & - fossil fertilizers quantity & - CER, CMR \\
\hline & E10 & - & - $\mathrm{CO}_{2} \mathrm{eq}$ emissions \\
\hline \multirow{4}{*}{ Pesticides use } & $\mathrm{A} 2, \mathrm{~B} 4, \mathrm{D} 8$ & - pesticides risk index & - Eutrophication \\
\hline & B5 & - dilution water volume & - CMR \\
\hline & D9 & - pesticides typology and quantity & - CER, CMR \\
\hline & E10 & - & - $\mathrm{CO}_{2}$ eq emissions \\
\hline \multicolumn{4}{|c|}{ 2. Pasta production phase } \\
\hline \multirow{4}{*}{$\begin{array}{l}\text { Industrial plant } \\
\text { management }\end{array}$} & B5 & - water volume & - CMR \\
\hline & $\mathrm{C} 7$ & $\begin{array}{l}\text { - technology level of the } \\
\text { equipment }\end{array}$ & - \\
\hline & D9 & - electricity consumption & - CER, CMR \\
\hline & E10 & - & - $\mathrm{CO}_{2}$ eq emissions \\
\hline \multicolumn{4}{|l|}{ 3. Transport phase } \\
\hline \multirow{4}{*}{$\begin{array}{l}\text { Transports of grains, } \\
\text { semolina and pasta }\end{array}$} & C6 & - logistic optimization level & - \\
\hline & C7 & - transport means typology & - \\
\hline & D9 & - fuel volume & - CER, CMR \\
\hline & E10 & - & - $\mathrm{CO}_{2}$ eq emissions \\
\hline \multicolumn{4}{|l|}{ 4. Cooking phase } \\
\hline \multirow{3}{*}{ Domestic use } & D9 & - energy consumption & - CER, CMR \\
\hline & B5 & - cooking water volume & - CMR \\
\hline & E10 & - & - $\mathrm{CO}_{2} \mathrm{eq}$ emissions \\
\hline
\end{tabular}

Note: Cumulated Energy Requirement (CER) and Cumulated Material Requirement (CMR) are defined in Section 2.1.2.

\subsubsection{EIAN Approach and Indicators}

The aim of the EIAN is the evaluation of comprehensive and potential impacts on a site-specific base, hypothesizing the interaction between the production system and the environment at the local scale. To reach this objective, several quantitative and/or qualitative indicators have been set. This approach takes inspiration from the Environmental Impact Assessment methodology as described in Italian and European legislation, but it is not at all the same administrative and technical procedure. The proposed approach allows to evaluate several pieces of information about the production chains which can potentially compromise the environment at a site-specific level, and afterwards integrates them with the potential global impacts assessed by the LCA. 
For the agricultural phase, the EIAN approach was implemented following the indications reported in [22]. As far as the crop choice is concerned, it is important to consider the plant and the environment as an integrated system, through particular site-specific indicators: In fact, crops highly suited to specific geographical areas are assumed to be more resistant to pests and climate variability. Moreover, crops, which are typically cultivated in a specific area, assure lower risks of biodiversity losses if compared to allochthonous crops or cultivars, introduced from other environments. On the other hand, the use of ancient cultivars could imply lower yields and lower efficiencies in water use (lower WUE), reducing the available water for agricultural uses in a specific geographical area, especially if the agricultural management is not optimized [23]. Soil management is also important for assessing environmental sustainability of the process: Crops characterized by a well-developed root system and the burying of agricultural residues are assumed to decrease the risk of erosion for a similar crop soil coverage. Erosion causes a loss of organic soil substances and leads to a loss of habitats, reducing water filtering and buffering functions with potentially negative effects on biodiversity. Moreover, lower levels of mechanization, if implemented, could assure a lower risk of soil fertility, compaction, and biodiversity losses, higher carbon matter storage, lower atmospheric emissions, and reduced energy requirements, etc. In any case, tillage operations, which assure an optimal soil structure and an adequate diffusion of liquids, can contribute to a more efficient use of water field resources and soil fertility preservation.

The type and the quantity of fertilizers can not only directly affect water quality, gaseous emissions, and biodiversity but also the soil's physical and chemical characteristics. At the same time, the spreading of the fertilization compounds implies direct emissions in agricultural land (e.g., atmospheric emissions, noise, soil compaction, etc.). Similar considerations can be made for pesticides, whose risks were evaluated according to the simplified approach elaborated by the Regional Agency for the Environment Protection in Tuscany, Italy (referred here as "ARPAT model") [24], hypothesizing the quality level of the waters and ecosystems of the considered geographical area. The ARPAT model sets three different indicators: the overall impact, the water impact, and the ecosystem impact. The model accuracy is comparable to that one of more complex models, which require significant effort and skill in analyzing all the active chemicals used and their effects on the environment (soil, water and organisms) [25]. In Reference [24] a useful list of the most common active chemicals is reported, indicating 3 impact indicators for each one; the overall expected risks for weeding and phytosanitary treatments can be calculated by multiplying these indicators per the dose of the active compound.

As far as the logistics of the production system is concerned, a direct influence on atmospheric emissions, fossil fuel requirement, noise emissions during transport and biodiversity, too, is given by transport distances, typology of means of transport, optimization level, and the potential increase of induced traffic at a local level.

Production processes and cooking phase are eventually responsible for raw materials and energy consumptions, and atmospheric emissions, too.

\subsubsection{LCA Methodology and Indicators}

Together with the evaluation of site-specific indicators (Table 1), a comparative LCA was carried out with the aim to evaluate global pressures caused by production processes, highlighting the main differences between high-quality and conventional pasta production processes. Attention was paid to single out which phases are more critical from an environmental point of view, and then possible solutions to reduce their impact are proposed.

LCA was carried out according to the ISO 14040 standard [10,11] by modeling the production chain through the Gemis ${ }^{\circledR}$ software version 4.95 (IINAS GmbH, Darmstadt, Germany) which consists of an open source analysis model and a database [26]. Moreover, the Biograce ${ }^{\circledR}$ GHG calculation tool version $4 \mathrm{~d}$ (IFEU GmbH, Heidelberg, Germany) [27] was also used for calculating $\mathrm{N}_{2} \mathrm{O}$ emissions due to the use of fertilizers. This methodology was applied to determine the following environmental pressures: 
- Effects on global warming, by quantifying $\mathrm{CO}_{2}$ equivalent emissions $\left(\mathrm{CO}_{2} \mathrm{eq}\right)$, accounting for carbon dioxide $\left(\mathrm{CO}_{2}\right)$, methane $\left(\mathrm{CH}_{4}\right)$ and nitrous oxide $\left(\mathrm{N}_{2} \mathrm{O}\right)$ emissions, and using the Global Warming Potential GWP100 factors [28];

- Primary energy consumption, by using the Cumulated Energy Requirement (CER), which represents the fossil energy required for extracting, manufacturing and disposal of raw and auxiliary materials;

- The Cumulated Material Requirement (CMR), by considering all the non renewable raw materials used throughout the whole life cycle;

- The Eutrophication index, by considering nutrients leaching in superficial and ground water.

LCA indicators used were limited to 4 to reduce the amount of inventory data necessary to perform the present analysis. Actually, the collection of additional data to take more indicators into account would require a significant effort in terms of time and resources, which were not available and could not be performed by all firms involved in the local production system, save by a simple estimation [29]. The 4 indicators were selected considering some results available in the literature. In fact, food, drink, tobacco, and narcotics areas account for an estimated 20 to $30 \%$ of most environmental impacts, except for eutrophication, which reaches 59\% [17]. This result is well known, even if environmental impacts arising across the entire life cycle ("from farm to fork") were studied in detail only for a few basic or processed foods. Actually, in the field of pasta production, specific studies have been carried out only in the last decades. This can be explained since plant-based products are those with lower impact levels. For example, cereal, bread, flour, and related products account for a little more than $1 \%$ of the EU's global warming potential (GWP) and of photochemical ozone creation potential, while the eutrophication potential is about $9 \%$ [17].

\subsubsection{System Boundaries and Functional Unit}

Both pasta production chains analyzed here consist of the following stages: durum wheat cultivation; milling of durum wheat to obtain semolina; pasta production and packaging; transportation, and wastes management. In the local scenario, it is necessary to account for an additional transport phase required to bring the product from the processing plant back to the farm where the pasta is marketed. Effects of the distribution phase from the producing industry to the final user were only estimated considering the different radius of the selling areas starting from the production plants for the two proposed chains. Domestic cooking consumptions were experimentally investigated for the high-quality pasta, while a simple estimation was considered for the conventional pasta.

In Figure 2 the main inputs (product) and outputs (residues) considered for environmental evaluations carried out in the present work are reported. However, a number of inputs and outputs have been excluded: materials needed for construction and maintenance of machines and equipments; construction materials for farm buildings and machines [30]; transport associated with fertilisers and other agrochemicals delivered to the farm; depuration treatments of production plant wastewater; energy and resources consumptions due to administrative activities; ink consumption and printing for the packaging of the product. Moreover, according to the Danish Environmental Protection Agency (2017), from $11 \%$ to $33 \%$ of cooked pasta is wasted on average, with even higher amounts occurring in European restaurants and schools. As a consequence, due to its high variability, in this work, the environmental impacts of food waste are not considered. 


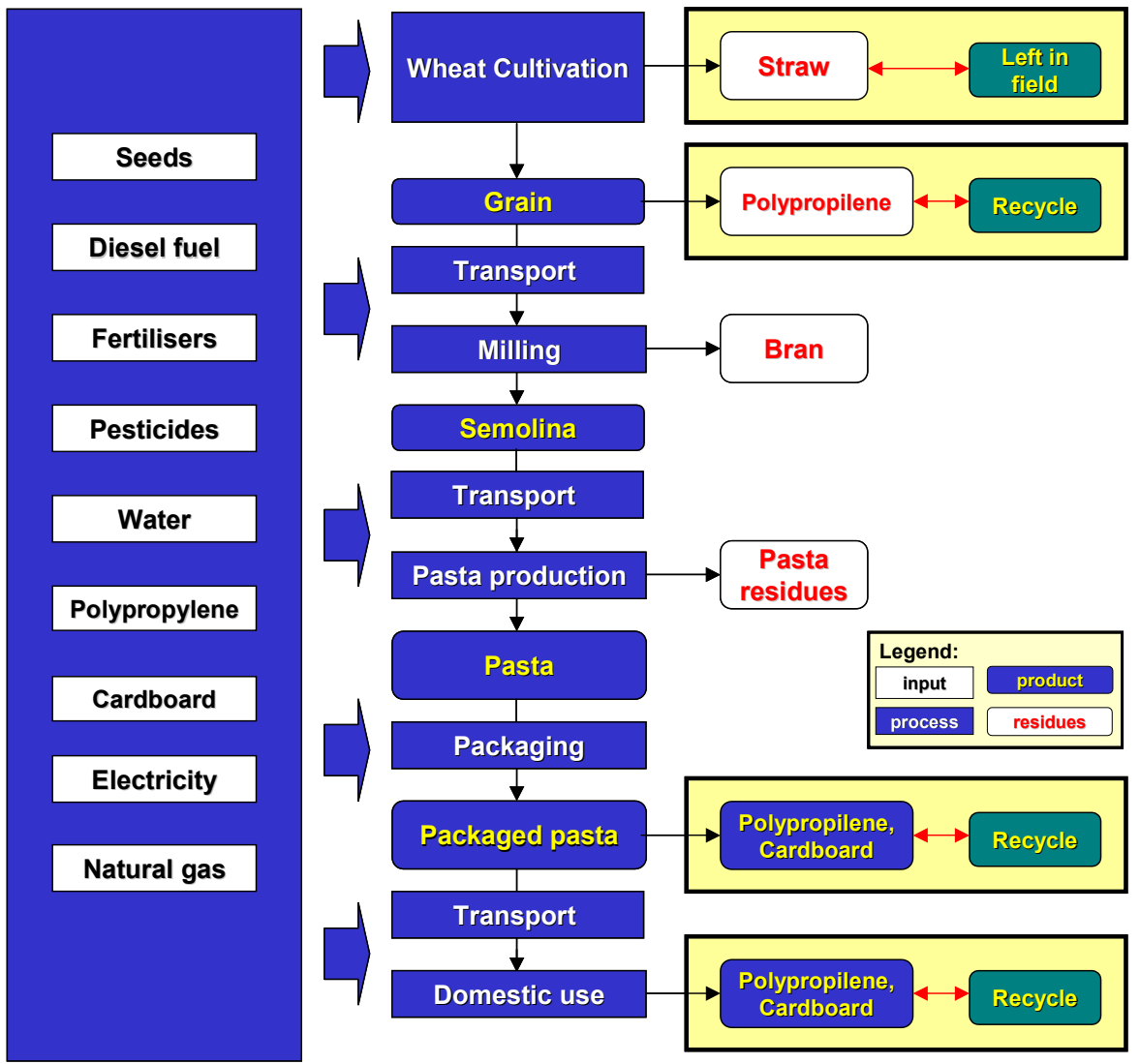

Figure 2. System boundaries of the pasta production.

As a functional unit (FU), $1 \mathrm{~kg}$ of dried pasta was considered. In particular, for the traditional pasta the whole system was modeled considering an annual production of $1500 \mathrm{~kg}$ of dried pasta, which represents the marketable product whose experimental data for the production of the traditional pasta are referred. This quantity is representative of the very small Italian firms which produce ancient grains pasta. In fact, the Italian statistical data [31] show that more than $50 \%$ of the Italian farms have agriculturally used land which measures less than 2 ha and, if the land is suitable for wheat cultivation, they choose ancient grains crops to obtain higher economic revenues. Instead, for the conventional pasta, an average production capacity of $75 \mathrm{t} /$ day [32] was assumed.

\subsection{Inventory Data Collection}

For what concerns the local scenario for high-quality pasta, the inventory data were collected in the three firms constituting the production chain, all located in Central Italy: Montepaldi farm (Firenze, Tuscany, Italy) for wheat cultivation; Molino Silvestri (Torgiano, Umbria, Italy) for wheat milling; Pastificio Artigianale Fabbri (Strada in Chianti, Tuscany, Italy) for pasta production. The pasta is commercialized with the Montepaldi brand. Data referred to the annual production of Montepaldi pasta. Agricultural data were collected through a questionnaire and represent the average mean of the years from 2012 to 2015, while, for the other phases, data were collected through direct measurements during the 2012 campaign. No significant differences were observed in terms of plant efficiency and input/output quantities during the observation period, so no criticisms emerged in the modeling process. However, since pasta is one of the most popular and widespread foods, its market demand is predominantly satisfied by conventional pasta, with a growing interest by consumers for conventional organic pasta [33]. In fact, pasta made with ancient grains and other special high-quality pasta typologies can only satisfy local and regional demands, in terms of attention to environmental sustainability and due to the lower production capability of local producers. For this 
reason, an industrial scenario supplying conventional pasta on a global scale was investigated, too. Finally, for both local and global scenarios the cooking phase was included: For the high-quality pasta, experimental data were used, while for the conventional pasta estimated data were considered as explained in detail in Section 3.1.

\section{Results}

\subsection{Description of Data Inventory}

Table 2 shows the data for both the high-quality (local) and conventional (global) pasta production scenarios. Concerning the local scenario, based on cultivation of ancient wheat cultivars and small-sized farms for the semolina and pasta production, an average yield of $2450 \mathrm{~kg} / \mathrm{ha}$ was calculated, accounting for $\mathrm{a}+/-36 \%$ of variability in the period from 2012 to 2015 due to different climatic condition. The wheat cultivar used in the farm under observation for the local scenario is "Senatore Cappelli", one of the most used Triticum durum cultivars in Italy, especially in Tuscany, even if other cultivars are becoming popular (e.g., "Timilia" and "Triticum turgidum", typical of Sicily). These old cultivars have a lower average yield with respect to modern ones [34], even if the quantity of sowing seed is similar, ranging from 200 to $220 \mathrm{~kg} / \mathrm{ha}$. The level of mechanization is normally higher for more intensive conventional wheat cultivation, due to the higher number, power, and weight of agricultural machines operating in field, which is characterized by a larger surface and higher accessibility (e.g., lower slope). Considering the fertilization inputs, even if there is not much difference in the use of potassium between the two scenarios, the conventional wheat production requires almost two times the nitrogen normally applied in the old variety cultivation (an average amount of $220 \mathrm{~kg} / \mathrm{ha} \mathrm{vs}$. $114 \mathrm{~kg} / \mathrm{ha}$ ), because of its higher production potentialities and the need to minimize the risk of low yield without caring about the risk of lodging. Moreover, the quantity of fertilizers for the Montepaldi farm are reduced since in this farm only one nitrogen fertilization is usually carried out. Pesticides are used in similar quantities, too. Significant differences have been detected in comparing the pasta production phase. Water consumption turned out to be higher for the high-quality pasta chain, which needs a water volume of $0.415 \mathrm{~kg} / \mathrm{FU}$ for the pasta production and the remaining quantity for the washing of equipment and machines. Contrarwise, for conventional pasta, the volume of water used for cleaning is significantly reduced because of larger quantity of pasta produced and the use of compressed air instead of water in the majority of the equipment. Therefore, in this case, the quantity of water needed for manufacturing pasta was similar, according to values reported in the literature, ranging between 22 and $30 \mathrm{~kg}$ per $1 \mathrm{~kg}$ of semolina [32,35].

Considering the transport phase, the high-quality pasta chain was less optimized in term of choice of means of transport and pathways, even if the distances were reduced. Particularly, for the local scenario, a significant energy consumption was required to cover a distance of $19 \mathrm{~km}$ from the pasta production plant to the Montepaldi farm, with 12 movements needed for moving the produced pasta. Concerning the global system, the transport distances were assumed considering an average comprehensive amount of $2.700 \mathrm{~km}$ shared in agricultural trucks (4\%), road transport (45\%) and ship transport (51\%), and an exporting rate of $25 \%$, for example, in North America.

Energy requirements for the domestic cooking of the Montepaldi pasta were measured carrying out an experimental test because of the lack of bibliographic data for cooking of ancient grain pasta: $300 \mathrm{~g}$ of pasta were cooked in 31 of water with $30 \mathrm{~g}$ of salt consuming $53 \mathrm{~g}$ of butane in 14 minutes. For the conventional pasta, the cooking phase was modeled considering an energy consumption of about $15 \mathrm{MJ} / \mathrm{FU}$ and a required amount of $10 \mathrm{~kg} / \mathrm{FU}$ as reported in [18]. The difference in the energy consumption between the two typologies of the pasta is probably due to the different cooking conditions (e.g., energetic source, pasta quantity, and type and shape of cooked pasta, etc.) and with respect to the cooking time. In fact, optimised cooking conditions are more easily assured for the traditional pasta due to its higher economic value which determines higher attention in the cooking phase to preserve the characteristics of the pasta and fulfill the consumers' expectations. 
Table 2. Inventory data for high-quality and conventional pasta production.

\begin{tabular}{|c|c|c|}
\hline Typology of the Pasta & High-Quality/Traditional & Commercial/Conventional \\
\hline Typology of the chain & local/regional & global \\
\hline Data source & Montepaldi pasta system & literature \\
\hline Reference years & $2012 ; 2013 ; 2014 ; 2015$ & - \\
\hline Geographical location & Central Italy & - \\
\hline \multicolumn{3}{|l|}{ Agricultural phase: } \\
\hline (1) Crop cultivar & $\begin{array}{l}\text { Senatore Cappelli; Timilia; } \\
\text { Triticum turgidum }\end{array}$ & - \\
\hline (2) Average yield [kg/ha] & 2450 & $4000^{(1)}$ \\
\hline (3) Seeds sowing [kg/FU] & 0.151 & $0.074^{(2)}$ \\
\hline \multicolumn{3}{|l|}{ (4) Agricultural operations } \\
\hline _ Diesel fupl consumntion & $\begin{array}{l}\text { Plowing; harrowing; sowing; } \\
\text { fertilizing; weeding and } \\
\text { phytosanitary treatments; } \\
\text { irrigation (optional); harvesting; } \\
\text { straw shredding; transports } \\
2718\end{array}$ & $\begin{array}{l}\text { Sowing; fertilizing; weeding } \\
\text { and phytosanitary treatments; } \\
\text { irrigation (optional); } \\
\text { harvesting; straw shredding; } \\
\text { transports }\end{array}$ \\
\hline - Diesel fuel consumption [MJ/FU] & 2.718 & $2.023^{(3)}$ \\
\hline
\end{tabular}

(5) Fertilization

- Fertilizers typology

Biammonic phosphate 18/46;

Nitrogen 46\%; P2O5 18\%; $\quad$ Nitrogen $46 \%$; P2O5 18\%; Urea

Ammonium nitrate N 27\%; Urea $\quad \mathrm{N} \mathrm{46 \%}$

- Total nitrogen volume $[\mathrm{kg} / \mathrm{FU}]$

$\mathrm{N} 46 \%$

$0.065 \quad 0.074^{(2)}$

- $\mathrm{P}_{2} \mathrm{O}_{5}$ quantity [kg/FU]

0.021

$0.010^{(2)}$

(6) Plant treatments:

- Herbicides typology

Axial; Granstar Ultra 50

- Insecticides/fungicides typology

Novel Duo; Binal Pro; Amistar

extra

- Total pesticides quantity [kg/FU]

0.0011

Tribenuron-methyl; pinoxaden

- Water consumption [kg/FU]

0.757

$0.0007^{(2)}$

$0.297^{(2)}$

$\begin{array}{lll}\text { (7) Residues production: } & & \\ \text { - Residues management } & \text { - shredded in field } & \text { - shredded in field } \\ \text { - Residues quantity [kg/FU] } & 2.533 & 1.760^{(1)}\end{array}$

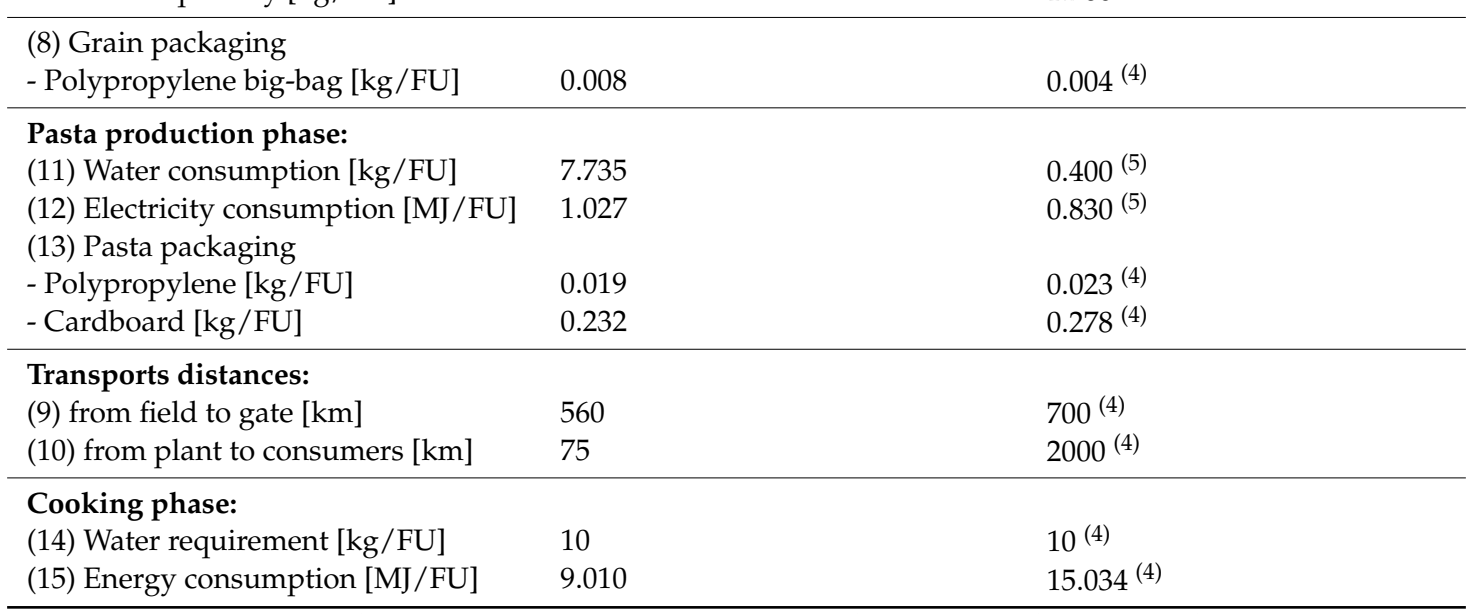

Literature sources: ${ }^{(1)}$ from [31]; ${ }^{(2)}$ from $[4,7] ;{ }^{(3)}$ from [36]; ${ }^{(4)}$ from $[18,37] ;{ }^{(5)}$ from [35]; ${ }^{(5)}$ from [32].

\subsection{Results of the Environmental Assessment}

Table 3 shows the results of the application of the integrated EIAN-LCA methodology presented in Section 2.1. In the agricultural phase, the high-quality pasta chain achieves a better performance due 
to a lower level of mechanization and a lower consumption of fuel, fertilizers, and pesticides. Similarly, the risk of pesticides diffusion in the ecosystems is lower, according to results obtained from the model proposed by ARPAT (Regional Agency for the Environment Protection in Tuscany, Italy) (Table 4). However, the commercial pasta chain requires a lower volume of water since the cultivation of modern cultivars is characterized by a higher WUE and exploits more efficient sprayers which allows one to use lower water volumes. Similar considerations can be made for water and electricity requirements in the industrial phase due to the larger plant sizes, the optimized equipment, and economy of scale.

Table 3. Results of the integrated EIAN-LCA methodology.

\begin{tabular}{|c|c|c|}
\hline Production Chain & $\begin{array}{l}\text { High-Quality/Tradit } \\
\text { Pasta }\end{array}$ & opal \\
\hline \multicolumn{3}{|l|}{ 1. Agricultural phase } \\
\hline - average yield [kg/ha] & 2450 & 4000 \\
\hline - WUE of cultivar & Low & high \\
\hline - adoption of autochthon cultivars & Yes & no \\
\hline - mechanization level & medium & high \\
\hline - fuel volume per ha & $4 \mathrm{GJ} / \mathrm{ha}$ & $6 \mathrm{GJ} / \mathrm{ha}$ \\
\hline - agrochemicals [kg/ha] & 149 & 252 \\
\hline - fertilisers [kg/ha] & 147 & 250 \\
\hline - dilution water $[\mathrm{kg} / \mathrm{ha}]$ & 1113 & 880 \\
\hline - pesticides quantity per ha & 1.9 & 2.2 \\
\hline - pesticides risk index & $2.83-3.05-2.52$ & $4.40-4.22-3.17$ \\
\hline - $\mathrm{CO}_{2}$ eq emissions [g/FU] & 1236 & 1217 \\
\hline - CER [MJ/FU] & 7.2 & 6.6 \\
\hline - CMR [kg/FU] & 0.176 & 0.117 \\
\hline - Eutrophication [mg/FU] & 7.264 & 5.242 \\
\hline \multicolumn{3}{|l|}{ 2. Pasta production phase } \\
\hline - technology level of the equipment & low & high \\
\hline - water volume $[\mathrm{kg} / \mathrm{FU}]$ & 7.735 & 0.400 \\
\hline - electricity amount [kg/FU] & 1.027 & 0.830 \\
\hline - $\mathrm{CO}_{2}$ eq emissions [g/FU] & 253 & 245 \\
\hline - CER [MJ/FU] & 3.6 & 3.7 \\
\hline - CMR [kg/FU] & 0.028 & 0.033 \\
\hline \multicolumn{3}{|l|}{ 3. Transport phase } \\
\hline - logistic optimization level & low & high \\
\hline - transport means typology & $\begin{array}{l}\text { agricultural truck + } \\
\text { road transport }\end{array}$ & $\begin{array}{l}\text { agricultural truck }+ \text { road } \\
\text { transport }+ \text { ship transport }\end{array}$ \\
\hline - fuel [MJ/FU] & 2.615 & 10.706 \\
\hline - $\mathrm{CO}_{2} \mathrm{eq}$ emissions [g/FU] & 217 & 302 \\
\hline - CER [MJ/FU] & 2.9 & 4.0 \\
\hline - CMR [kg/FU] & 0.001 & 0.003 \\
\hline \multicolumn{3}{|l|}{ 4. Cooking phase } \\
\hline - energy [MJ/FU] & 9 & 15 \\
\hline - cooking water [kg/FU] & 10 & 10 \\
\hline - $\mathrm{CO}_{2}$ eq emissions [g/FU] & 1242 & 1114 \\
\hline - CER [MJ/FU] & 19.1 & 18.2 \\
\hline - CMR [kg/FU] & 0.004 & 0.137 \\
\hline $\begin{array}{l}\text { worst performance } \\
\text { (value } 2 \text { ) }\end{array}$ & $\begin{array}{l}\text { equivalent } \\
\text { performance } \\
\text { (value } 1 \text { ) }\end{array}$ & $\begin{array}{l}\text { better performance } \\
\text { (value } 0 \text { ) }\end{array}$ \\
\hline
\end{tabular}


Table 4. Results of the Regional Agency for the Environment Protection in Tuscany, Italy (ARPAT) model.

\begin{tabular}{|c|c|c|c|c|}
\hline & Overall Impact & Water Impact & Ecosystem Impact & Dose $[\mathrm{kg} / \mathrm{ha}]$ \\
\hline \multicolumn{5}{|c|}{ Pesticides for high-quality/traditional pasta } \\
\hline Azoxystrobin & 2 & 2 & 2 & 0.22 \\
\hline Cioquintocet-mexyl & 2 & 2 & 2 & 0.02 \\
\hline Cyproconazole & 3 & 3 & 2 & 0.09 \\
\hline Pinoxaden & 2 & 1 & 2 & 0.09 \\
\hline \multirow{2}{*}{ Procloraz } & 2 & 2 & 2 & 0.35 \\
\hline & 2 & 2 & 2 & 0.36 \\
\hline Propiconazole & 2 & 2 & 2 & 0.09 \\
\hline Tetraconazole & 2 & 2 & 2 & 0.06 \\
\hline \multicolumn{2}{|c|}{ Thifensulfuron-methyl1 } & 2 & 1 & 0.31 \\
\hline \multirow[t]{2}{*}{ Tribenuron-methyl } & 2 & 2 & 1 & 0.31 \\
\hline & 2.83 & 3.05 & 2.52 & 1.90 \\
\hline \multicolumn{5}{|c|}{ Pesticides for the conventional pasta } \\
\hline Tribenuron-methyl & 2 & 2 & 1 & 1.23 \\
\hline Pinoxaden & 2 & 1 & 2 & 0.18 \\
\hline Propiconazole & 2 & 2 & 2 & 0.30 \\
\hline \multirow[t]{2}{*}{ Azoxystrobin } & 2 & 2 & 2 & 0.50 \\
\hline & 4.40 & 4.22 & 3.17 & 2.20 \\
\hline
\end{tabular}

Looking at the transport phase, the conventional pasta chain appears to be better organized in terms of logistics and characteristics of the means of transport, even if the higher distances to be covered determine significant impacts in terms of atmospheric pollution and noise. No significant differences have been observed in the cooking phase, which, however, turned out to have a considerable impact on the whole process. In fact, it can be observed that the higher average energetic consumption for the conventional pasta is balanced by the advantages due to higher crop yields and production plants efficiencies, as illustrated in Table 3. A deeper insight into LCA results shows how the high-quality pasta achieved an overall better performance than the conventional one (1706 vs. $1765 \mathrm{~g} \mathrm{CO}_{2} \mathrm{eq} / \mathrm{FU}$; 13.7 vs. $14.3 \mathrm{MJ} / \mathrm{FU} ; 109$ vs. $\left.126 \mu \mathrm{gPO}_{4}{ }^{-} / \mathrm{FU}\right)$, substantially due to the transport phase. Figure 3 reports detailed LCA results for the two chains. In particular, looking at the $\mathrm{CO}_{2} \mathrm{eq}$ emissions, the main critical phases are represented by wheat cultivation and domestic pasta consumption, even if, as far as the CER results are concerned, domestic cooking represents 56 to $58 \%$ of the total fossil energy consumption. Furthermore, based on the results illustrated in Table 3, it is possible to assess the environmental pressures associated with the two pasta production chains (Figure 4). The high-quality pasta chain shows a better performance in terms of risk reduction for soil degradation and agrobiodiversity loss, as well as consumption of non-renewable resources; this is mainly due to the use of lower quantities of chemicals, a lower mechanization level in the agricultural phase, and the use of ancient grains. However, the conventional pasta chain prevails in terms of a more efficient exploitation of land and water resources, due to higher yields and the use of more efficient sprayers, and also in reducing noise emitted by the overall production equipment. 


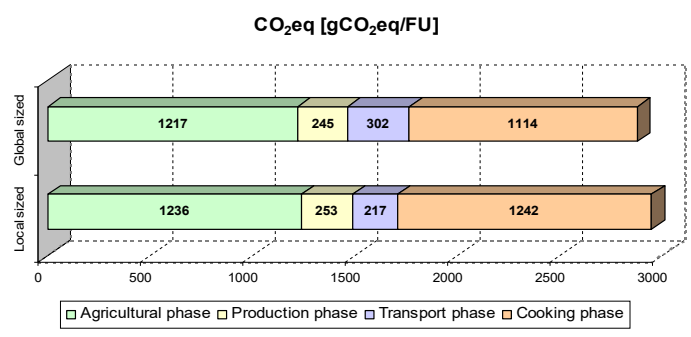

CER [MJ/FU]

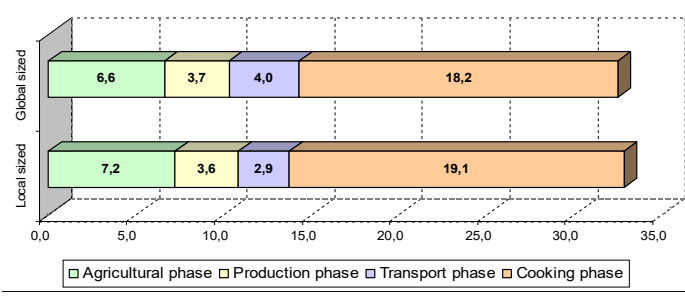

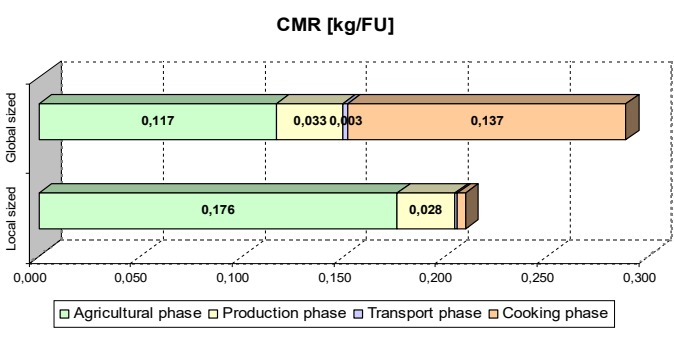

Eutrophication $\left[\mathrm{HgPO}_{4}^{-} / \mathrm{FU}\right]$

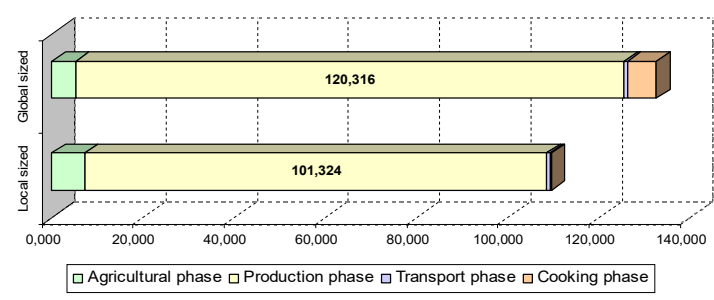

Figure 3. Life Cycle Assessment (LCA) results for high-quality/local and conventional/global pasta chains.

\begin{tabular}{|c|c|c|c|}
\hline Production chain: & \multicolumn{3}{|c|}{ High quality / traditional pasta } \\
\hline A-Soil & B - Water & $C-$ Air & D-Resources \\
\hline - Land use (A1) & - Pollution (B4) & - Pollution (C6) & - Biotic: agrobiodiversity (D8) \\
\hline - Pollution (A2) & \multirow{2}{*}{$\begin{array}{l}\text { - Abstraction or } \\
\text { Diversion (B5) }\end{array}$} & - Noise (C7) & - Abiotic: non renewable (D9) \\
\hline - Degradation (A3) & & \multicolumn{2}{|c|}{ E - Climate change (E10) } \\
\hline Production chain: & \multicolumn{3}{|l|}{ Conventional pasta } \\
\hline A-Soil & B - Water & $\mathrm{C}-\mathrm{Air}$ & D - Resources \\
\hline - Land use (A1) & - Pollution (B4) & - Pollution (C6) & - Biotic: agrobiodiversity (D8) \\
\hline - Pollution (A2) & \multirow{2}{*}{$\begin{array}{l}\text { - Abstraction or } \\
\text { Diversion (B5) }\end{array}$} & - Noise (C7) & - Abiotic: non renewable (D9) \\
\hline - Degradation (A3) & & \multicolumn{2}{|c|}{ E - Climate change (E10) } \\
\hline worst performar & equival & ent performance & better performance \\
\hline
\end{tabular}

Figure 4. Assessment of the environmental pressures for the high-quality and conventional pasta production.

\section{Discussion of the Environmental Assessment and Future Improvements}

Several authors have analyzed LCA of pasta production in small- and medium-sized industries based in southern Italy; some of them have also analyzed the Environmental Input and Output Life Cycle Assessment (EIO-LCA) [38], which uses economy intersectoral matrices to include the whole economic system in the analysis, without cut-offs or other limitations of the system borders. Results of these studies are coherent and point out that the phase with the highest impact in the production process is wheat cultivation, while the one with the least impact is represented by semolina production, if considering pollutant release as the most important aspect [39].

The first detailed assessment of the environmental impact of the whole manufacturing process, with a cradle-to-grave approach, was carried out in 2007 [18]. The authors of this study considered the energetic flows, the consumption of materials and the emissions of pollutants of the production and distribution of durum wheat pasta in the Italian market, finding that the cultivation phase accounted for most of the environmental load. In 2009, the Barilla Group produced a detailed LCA and a 
preliminary EPD of a $500 \mathrm{~g}$ unit produced in Italy and packed in a paperboard box. As a result of this analysis, gross energy requirements were of $17 \mathrm{MJ}$, out of which $4.7 \mathrm{MJ}$ was used in the durum wheat production, with a Global Warming Potential (GWP) of $1.3 \mathrm{~kg}$ of $\mathrm{CO}_{2}$ and a water consumption of $7.2 \mathrm{~kg}$. The cooking phase turned out to be the most critical one in the whole process. The Barilla study was updated in 2012 and 2014, and extended to all Barilla processing facilities in the world, finding a number of relevant actions useful for mitigating the environmental impact of each process phase [37]. Among these, it is worth citing the adoption of low input agronomic practices in the cultivation phase, such as the introduction of dicotyledons, where cereal-only rotation is practiced, which can lead to a reduction in greenhouse gas emissions of up to $36 \%$. In addition, this practice reduces the risk of contamination by mycotoxins and increases the net income for farmers by up to 31\% [40].

For $\mathrm{CO}_{2}$ eq emissions for the high-quality pasta production chain, the agricultural phase seems to be the on with the most impact. A strategy which is suggested to reduce such emissions is given by the organic farming approach, which avoids the use of the fertilizers and pesticides, with the additional opportunity of using by-products for fertilizing. As a matter of fact, the Montepaldi farm adopted organic management during 2016-2017: The same cultivars were grown with an average yield of $2623 \mathrm{~kg} / \mathrm{ha}$. The mechanization level was increased, and consequently, the fuel consumption rose to $6500 \mathrm{MJ} / \mathrm{ha}$. Furthermore, LCA results show a better overall performance of the high-quality pasta with respect to the conventional one: 1270 vs. $1765 \mathrm{gCO}_{2}$ eq/FU; 11.4 vs. $14.3 \mathrm{MJ} / \mathrm{FU} ; 33 \mathrm{~g} / \mathrm{FU}$ vs. $152 \mathrm{~g} / \mathrm{FU} ; 110 \mathrm{vs} .126 \mathrm{\mu gPO}_{4}^{-} / \mathrm{FU}$. Moreover, these results could be even lower if by-products were used for fertilizing, due to the obtaining of "credits" in the LCA assessment. An organic certification could increase the value of the product further, and could be considered as an additional motivation for consumers. For conventional pasta production, a reduction of $\mathrm{CO}_{2}$ emissions in the agricultural phase could be pursued, too, by identifying the minimum quantity of fertilizers which guarantees suitable yields. Furthermore, another strategy which might be interesting for producers, is to convert part of the production to organic farming.

Considering the production phase of high-quality pasta, the drying phase is the most critical in terms of energy consumption, environmental impacts, and expenditure, indicating the need for improvement. The Italian traditional high-quality pasta production is based on a low-temperature long-time (LT-LT) drying process [41], which is recognized as a quality parameter by consumers. However, LT-LT energy consumption could be reduced by the introduction of new technologies, such as microwaves and pulsed electric fields [42]. Furthermore, in the Montepaldi case, the impacts due to the transport phase should be significantly reduced by avoiding raw material transportation to a mill at a greater distance, and by averting transportation of semi-finished products to a distant pasta manufacturing plant. In fact, small production companies should be independent and carry out in-house cultivation, milling, and pasta production to be competitive and assure safe products with lower environmental impacts. In addition, a proper logistic should be planned for pasta distribution. On the other hand, in the global scenario, it is assumed that big companies have already optimized logistics and transport to minimize costs; as a consequence, opportunities of reducing their associated impacts are minimal.

Concerning $\mathrm{CO}_{2}$ emissions related to the cooking phase, it is important to highlight that part of the high-quality pasta production is dispatched to restaurants, where the use of pasta cookers allows to save up to $60 \%$ of energy and $38 \%$ of water [12]. On the contrary, domestic consumption mainly uses the conventional product, so that, in this case, the most promising energy reduction strategy consists in the improvement of household cooking practices, which can lead to savings of up to 95\% [43]. Among these, a substantial reduction of carbon footprint and operating costs in domestic cooking of pasta can be obtained by using an induction hob and a pan covered by a lid: the power rate should be initially set to the maximum level, to make the cooking water boil faster, and then to the minimum level necessary to keep constant the water temperature and allow starch gelatinization. This would allow a carbon footprint reduction of up to $670 \mathrm{~g} \mathrm{CO}_{2} \mathrm{eq}$ and operating cost reductions up to $0.47 €$ per $\mathrm{kg}$ of pasta [44]. 


\section{Conclusions}

The results of the present work show that the traditional pasta may cause impacts of $1.706 \mathrm{~kg}$ of $\mathrm{CO}_{2}$ eq emissions, $13.7 \mathrm{MJ}$ of fossil energy consumption, $0.206 \mathrm{~kg}$ of non-renewable resource, and $109 \mu \mathrm{gPO} 4-/ \mathrm{FU}$ per each $\mathrm{kg}$ of dried pasta produced, while the conventional pasta production accounts for $1.765 \mathrm{~kg}$ of $\mathrm{CO}_{2}$ eq emissions, $14.3 \mathrm{MJ}$ of fossil energy consumption, $0.152 \mathrm{~kg}$ of non-renewable resource, and $126 \mu \mathrm{gPO} 4-/ \mathrm{FU}$ per each $\mathrm{kg}$ of dried pasta produced, without considering both the distribution and domestic cooking phases.

As a consequence, the high-quality pasta chain causes environmental impacts which are comparable to those of the conventional chain. Nevertheless, following the suggestions proposed here, $\mathrm{CO}_{2}$ emissions of the high-quality pasta production chain could be significantly reduced, obtaining significant improvements in LCA assessment, when compared to the conventional pasta production in a global scenario where margins for improvement are lower.

However, though the LCA does not highlight significant differences between the high-quality and conventional pasta production chains, the proposed integrated EIAN-LCA approach shows that the high-quality chain has a lower impact on soil degradation, agrobiodiversity losses, and on the consumption of non-renewable resources. On the other side, due to higher yields, higher equipment efficiency, and lower noise emissions of the involved machines, the conventional chain has a lower impact in terms of land use, water abstraction and/or diversion, and noise emissions. In conclusion, the developed combined EIAN-LCA approach allows to evaluate several indicators, belonging not only to LCA standards but for an innovative and comprehensive assessment of pasta production chains. This approach appears able to suggest how to enhance the various production phases, also considering the peculiarities of the geographical and technological context, to improve the sustainability of food production.

Author Contributions: Conceptualization, E.C., L.R., A.C., F.G.P. and P.B.; methodology and software, L.R.; validation, F.G.P. and L.R.; formal analysis, P.B. and L.R.; data curation, L.R. and P.B.; writing, original draft preparation, review and editing: L.R., A.C. and F.G.P.; supervision, E.C., L.R. and P.B.

Funding: This research received no external funding.

Acknowledgments: The authors gratefully acknowledge the Montepaldi farm for supplying the inventory data of the high-quality pasta chain.

Conflicts of Interest: The authors declare no conflict of interest.

\section{References}

1. EC-European Commission. Guidance Document Describing the Food Categories in Part E of Annex II to Regulation (EC) No 1333/2008 on Food Additives. 2008. Available online: http: / / ec.europa.eu/food/ safety/docs/fs_food-improvement-agents_guidance_1333-2008_annex2.pdf (accessed on 1 October 2018).

2. Andrade-Sanchez, P.; Ottman, M.J. Determination of Optimal Planting Configuration of Low Input and Organic Barley and Wheat Production in Arizona; College of Agriculture, University of Arizona: Tucson, AZ, USA, 2014.

3. Bali, K. Wheat Fertilization Practices in the Imperial Valley, California Wheat Commission Research Report, 2010-2011. Available online: http:/ /www.californiawheat.org/uploads/resources/400/bali-wheatfertilization-practices-research-report.pdf (accessed on 1 October 2018).

4. DAF-Dep. of Agriculture and Fisheries. Durum Wheat in Queensland. 2012. Available online: https: / /www.daf.qld.gov.au/business-priorities/plants/field-crops-and-pastures/broadacre-fieldcrops/wheat/durum-wheat (accessed on 17 July 2018).

5. Ferrari, E. Interview to Emilio Ferrari Responsible for Durum Wheat Purchase at Barilla SpA, IL Piacenza. 2018. Available online: http://www.ilpiacenza.it/economia/barilla-tutta-1-importanza-dei-controlli-difiliera-a-tutela-della-pasta-di-grano-duro-made-in-italy.html (accessed on 17 July 2018).

6. Kneipp, J. Durum Wheat Production, NSW Department of Primary Industries; Tamworth Agricultural Institute: Calala, Australia, 2008. Available online: https://www.dpi.nsw.gov.au/_data/assets/pdf_file/0010/ 280855/Durum-wheat-production-report.pdf (accessed on 31 December 2018). 
7. SADGA-The Southern Australia Durum Growers Association Inc. Growing a Successful Durum Crop. 2018. Available online: https://durumgrowerssa.org.au/industry-news/growing-a-successful-durum-crop (accessed on 17 July 2018).

8. Samson, M.F.; André, C.; Audigeos, D.; Besombes, C.; Braun, P.; Cassan, D.; Chiron, A.; Cochard, M.; Dusautoir, J.C.; Kessler, J.P.; et al. Durum wheat pasta with a good quality and a reduced nitrogen fertilization: Is it possible? In Proceedings of the 15th International Cereal and Bread Congress (ICBC 2016), Istanbul, Turkey, 18-21 April 2016.

9. ISO 14025:2006. Environmental Labels and Declarations_-Type III Environmental Declarations_Principles and Procedures; International Organization for Standardization (ISO): Geneva, Switzerland, 2006.

10. ISO 14040:2006. Environmental Management_Life Cycle Assessment_Principles and Framework; International Organization for Standardization (ISO): Geneva, Switzerland, 2006.

11. ISO 14044:2006. Environmental Management_Life Cycle Assessment_Requirements and Guidelines; International Organization for Standardization (ISO): Geneva, Switzerland, 2006.

12. Fusi, A.; Guidetti, R.; Azapagic, A. Evaluation of environmental impacts in the catering sector: The case of pasta. J. Clean. Prod. 2016, 132, 146-160. [CrossRef]

13. Ruini, L.; Marino, M.; Pignatelli, S.; Laio, F.; Ridolfi, L. Water footprint of a large-sized food company: The case of Barilla pasta production. Water Res. Ind. 2013, 1, 7-24. [CrossRef]

14. Sobczyk, A.; Pycia, K.; Stankowski, S.; Jaworska, G.; Kuźniar, P. Evaluation of the rheological properties of dough and quality of bread made with the flour obtained from old cultivars and modern breeding lines of spelt (Triticum aestivum ssp. spelta). J. Cereal Sci. 2017, 77, 35-41. [CrossRef]

15. Teuber, R.; Dolgopolova, I.; Nordström, J. Some like it organic, some like it purple and some like it ancient: Consumer preferences and WTP for value-added attributes in whole grain bread. Food Qual. Prefer. 2016, 52, 244-254. [CrossRef]

16. Liu, J.; Orr, S. Water footprint overview in the governmental, public policy, and corporate contexts. In On the Water Front: Selections from the 2009 World Water Week in Stockholm; Lundqvist, J., Ed.; Stockholm International Water Institute: Stockholm, Sweden, 2010; pp. 73-79.

17. Foster, C.; Green, K.; Bleda, M.; Dewick, P.; Evans, B.; Flynn, A.; Mylan, A. Environmental Impacts of Food Production and Consumption: A Report to the Department of Environment, Food and Rural Affairs, Manchester Business School; Defra: London, UK, 2006.

18. Bevilacqua, M.; Braglia, M.; Carmignani, G.; Zammori, F.A. Life Cycle Assessment of Pasta Production in Italy. J. Food Qual. 2007, 30, 932-952. [CrossRef]

19. Gärtner, S.; Köppen, S.; Detzel, A.; Häfele, S.; Münch, J.; Reinhardt, G.; Rettenmaier, N.; Recchia, L.; Chiaramonti, D. Report on the Results of the Environmental Implications, Life Project "Vegetable Oil Initiative for a Cleaner Environment"; GA LIFE06 ENV/IT00257; CREAR-University of Florence: Firenze, Italy, 2009.

20. Kretschmer, W.; Capaccioli, S.; Chiaramonti, D.; De Bari, I.; Frattini, A.; Giovannini, A.; Janssen, R.; Keller, H.; Langer, M.; Liden, G.; et al. Integrated Sustainability Assessment of Biolyfe Second Generation Bioethanol, FP7 Project "Second Generation Bioethanol Process: Demonstration Scale for the Step of Lignocellulosici Hydrolysis and Fermentation"; GA 239204; IFEU GmbH: Heidelberg, Germany, 2013.

21. EEA-European Environmental Agency. Estimating the Environmentally Compatible Bioenergy Potential from Agriculture; Technical Report n.12/2007; EEA: Copenhagen, Denmark, 2008; ISBN 978-92-9167-969-0, ISSN 1725-2237. [CrossRef]

22. Rettenmaier, N.; Harter, R.; Himmler, H.; Keller, H.; Kretschmer, W.; Müller-Lindenlauf, M.; Reinhardt, G.; Scheurlen, K.; Schröter, C. Integrated Sustainability Assessment of the BIOCORE Biorefinery Concept (D 7.6), FP7 Project "BIOCOmmodity Refinery Project"; GA 241566; IFEU GmbH: Heidelberg, Germany, 2014.

23. Siddique, K.H.M.; Tennant, D.; Perry, M.W.; Belford, R.K. Water use and water use efficiency of old and modern wheat cultivars in a Mediterranean type environment. Aust. J. Agric. Res. 1990, 41, 431-447. [CrossRef]

24. ARPAT (Regional Agency for Environment Protection of Tuscany, Italy). Fitofarmaci-Proposta di un Indicatore di Pressione Elaborando Proprietà Ambientali e dati di Utilizzo dei Prodotti Fitosanitari; ARPAT-Regione Toscana: Firenze, Italy, 2015.

25. Recchia, L.; Sarri, D.; Rimediotti, M.; Boncinelli, P.; Cini, E.; Vieri, M. Towards the environmental sustainability assessment for the viticulture. J. Agric. Eng. 2018, 49, 19-28. [CrossRef]

26. Gemis $^{\circledR}$. Available online: http://iinas.org/gemis.html (accessed on 1 October 2018). 
27. Biograce. Available online: http:/ / www.biograce.net/ (accessed on 16 August 2018).

28. IPCC. Third Assessment Report-Climate Change; IPCC: Geneva, Switzerland, 2001.

29. Woodhouse, A.; Davis, J.; Pénicaud, C.; Östergren, K. Sustainability checklist in support of the design of food processing. Sustain. Prod. Consum. 2013, 16, 110-120. [CrossRef]

30. Chiaramonti, D.; Recchia, L. Is life cycle assessment (LCA) a suitable method for quantitative CO2 saving estimations? the impact of field input on the LCA results for a pure vegetable oil chain. Biomass Bioenergy 2010, 34, 787-797. [CrossRef]

31. Agristat. Available online: http:/ / agri.istat.it (accessed on 31 December 2018).

32. BREF. Food, Drink and Milk Industries; IPCC: Geneva, Switzerland, 2006.

33. Babula, R.A.; Rich, K.M. A Time-Series Analysis of the US Durum Wheat and Pasta Markets. J. Food Distrib. Res. 2001, 32, 1-19.

34. Quaranta, F.; Belocchi, A.; Fornaia, M.; Ripa, C.; D’Egidio, M.G. Le Varietà di Frumento duro in Italia: Risultati della rete Nazionale di Sperimentazione 1999-2012; CRA-Mipaaf: Roma, Italy, 2013.

35. Heidari, M.D.; Huijbregts, M.A.J.; Mobli, H.; Omid, M.; Rafiee, S.; van Zelm, R. Regionalised life cycle assessment of pasta production in Iran: Damage to terrestrial ecosystems. J. Clean. Prod. 2017, 159, 141-146. [CrossRef]

36. ENAMA. Prontuario dei Consumi di Carburante per L'impiego Agevolato in Agricoltura; ENAMA: Roma, Italy, 2005.

37. Barilla. Environmental Product Declaration of Dry Semolina Pasta from Durum Wheat. 2011. Available online: www.environdec.com/en/Detail/?Epd=7699 (accessed on 1 October 2018).

38. Notarnicola, B.; Mongelli, I.; Tassielli, G.; Nicoletti, G.M. Environmental input-output analysis and hybrid approaces to improve the set up of the pasta life cycle inventory. J. Commod. Sci. 2004, 43, 59-86.

39. Notarnicola, B.; Tangari, C.; Tassielli, G.; Giungato, P.; Nardone, E. Comparison analysis of several LCA studies on pasta. In Proceedings of the International Conference "LCA \& Eco-Innovation in Italy: Good Practices and Success Stories", Ecomondo 2008, Rimini, Italy, 7 November 2008.

40. Ruini, L.; Ferrari, E.; Meriggi, P.; Marino, M.; Sessa, F. Increasing the sustainability of pasta production through a life cycle assessment approach. In Proceedings of the International Workshop Advances in Cleaner Production "Integrating Cleaner Production into Sustainability Strategies", São Paulo, Brazil, 22-24 May 2013.

41. West, R.; Seetharaman, K.; Duizer, L.M. Effect of drying profile and whole grain content on flavour and texture of pasta. J. Cereal Sci. 2013, 58, 82-88. [CrossRef]

42. De Pilli, T.; Giuliani, R.; Derossi, A.; Severini, C. Study of cooking quality of spaghetti dried through microwaves and comparison with hot air dried pasta. J. Food Eng. 2009, 95, 453-459. [CrossRef]

43. Hager, T.J.; Morawicki, R. Energy consumption during cooking in the residential sector of developed nations: A review. Food Policy 2013, 40, 54-63. [CrossRef]

44. Cimini, A.; Moresi, M. Energy efficiency and carbon footprint of home pasta cooking appliances. J. Food Eng. 2010, 204, 8-17. [CrossRef]

(c) 2019 by the authors. Licensee MDPI, Basel, Switzerland. This article is an open access article distributed under the terms and conditions of the Creative Commons Attribution (CC BY) license (http:/ / creativecommons.org/licenses/by/4.0/). 